\title{
IN RETROSPECT
}

\section{Diagnosing deep similarity in nature}

\author{
On the Nature of Limbs: A Discourse \\ by Richard Owen \\ University of Chicago Press: 2007. 119 pp. \\ $\$ 50$ (hbk), \$20 (pbk)
}

\section{Michael Coates}

On the night of 9 February 1849, Richard Owen, the pre-eminent Victorian anatomist who later founded London's Natural History Museum, delivered a public lecture at the Royal Institution of Great Britain. In a strident discourse that set the stage for Charles Darwin's account of evolution, Owen revealed similarities in biological forms from species to species that suggested some underlying ideal plan or archetype. He sought to debunk the prevailing view that anatomical pattern could be explained as a consequence of biological function. With example after example, Owen hammered home the point that structural correspondences between species, or even between parts of the same individual, cannot be explained simply by adaptation. The echoes of his words still reverberate.

Owen's ideas contributed directly to Darwin's synthesis of evidence for evolution a decade later. Where Owen saw an archetype - an abstracted common pattern - Darwin glimpsed an ancestor or ancestral condition. "Nothing," Darwin wrote in On the Origin of Species, "can be more hopeless than to attempt to explain this similarity of pattern in members of the same class, by utility or by the doctrine of final causes."

My first reaction to re-reading Owen's tour de force was that it must have been a slow evening. In long-winded prose, Owen pores over the minutiae of vertebrate limb bones, the mistakes of lesser scientists and the relationship between observed anatomy and his theoretical template for vertebrate-kind. Many readers might be tempted to skip the text and turn to the pictures, especially the classic plate depicting Owen's own vertebrate archetype, like a skeletal zeppelin hovering above human, fish, bird and other osteological comparisons. Incidentally, the figure caption is vast, and almost qualifies as further discourse on the themes in the main text. Yet it is worth persisting. Brian Hall's preface and introductory essays by Mary P. Winsor, Jennifer Coggon, Ron Amundsen and Kevin Padian bring out the subtleties of Owen's arguments and place them in a historical and social context, among the philosophical turmoil of biology in the early to mid-nineteenth century.

A decade before Darwin's On the Origin of Species, Owen very nearly sketched a theory of evolutionary transformation, fragments of which appear here. However, as Padian describes, such were the sociopolitical and philosophical strains on Owen's position that he stalled at the final intellectual leap. Owen's patrons were of the Oxbridge-educated establishment - adherents to the natural theology of the 'argument from design' (for the existence of God) as advocated most influentially by William Paley (now sadly repackaged with a molecular gloss by the proponents of 'intelligent design').

Uncomfortably for Owen, his explanations of form raised the loathsome prospect of atheism. They drew heavily on the ideas of European philosophers and anatomists, such as Lorenz Oken and Carl Gustav Carus, bringing British comparative biology up to speed with that on the continent. That these notions required no beneficent deity, which created perfect organisms with optimally designed body parts, placed the ambitious Owen in a professionally risky position. Consequently, On the Nature of Limbs includes some curiously religious passages about the quest for the archetype, equating it with the discovery of the 'divine plan' (an aspect of Victorian academia of interest, perhaps, to readers of Philip Pullman's His Dark Materials trilogy).
As an account of the details of vertebrate limbs and fins, On the Nature of Limbs could be filed away as of historical interest only. But it remains an excellent source for those interested in how we identify and interpret pattern in nature. A dissertation on similarity, conservation and variability in form, it addresses issues of enduring interest to systematic biologists as well as to the revitalized field of evolutionary developmental biology. The book is a superb vehicle for the exploration of homology, Owen's most lasting legacy to modern biology. Homology is the diagnosis of deep similarity in nature, based upon simple criteria - position, development and structure. Manifestations of homology have been explained variously in terms of archetypes and evolution, separately and in combination, and a reading of Owen's discourse offers a refreshed perspective on this sometimes slippery concept.

Ron Amundsen emphasizes Owen's stand for a structuralist perspective in biology as being an essential step on the road to current understanding that adult form and embryonic development are contingent upon evolutionary history. Even so, Owen remained resolutely in the camp of non-evolutionary biologists. For Owen, just as fins and limbs were variations on the extremities of an ideal vertebra, so actual species could be thought of as departures "from the first embodiment of the Vertebrate Idea under its old Ichthyic vestment, until it became arrayed in the glorious garb of the Human form".

A contentious character, Owen is all too easily dismissed as the self-promoting, vitriolic critic of Darwin. On the Nature of Limbs is a timely reminder that his work was - is - of real value.

Michael Coates is associate professor in the department of organismal biology and anatomy at the University of Chicago, Chicago, Illinois 60637, USA. He is a co-editor of Evolution \& Development.

\section{FASHION Fleeting fabrics}

Imagine if last season's dress or suit vanished of its own accord after some expiration date. In a comment on our disposable culture, Valentino-trained fashion designer Helen Storey is using know-how from materials science to make a show of frocks that dissolve slowly in water.

Her couture creations, made from biodegradable polymer threads, are being publicly drowned in a gallery window near London's busy shopping hub, Oxford Street. Storey has long harboured concerns about our attitudes to waste and recycling, and during her career has woven plastic refuse bags and reused rags to make boas and evening gowns.

To realize her idea of evanescent products, such as packaging that disappears as its contents expire, Storey contacted chemist Tony Ryan, of the University of Sheffield, UK, after hearing him on the radio. Their Wonderland collaboration has produced new textiles and

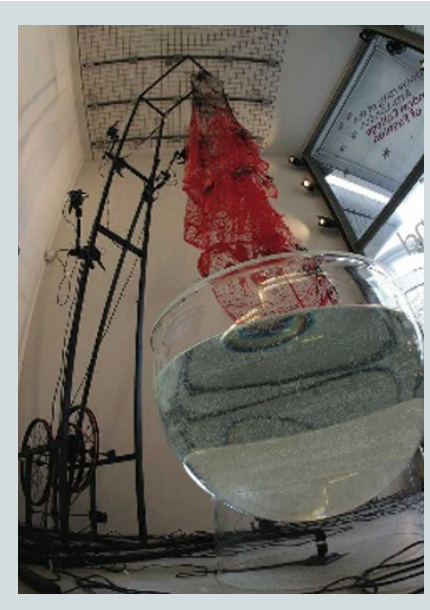

several patented products, including a water-purification device, a biodegradable bottle and orthopaedic shoes.

Ryan relishes the injection of wild ideas into his lab: "Helen really pushes the boundaries of our knowledge, but we share the dream of a world that uses its resources more responsibly."

Wonderland is showing at London College of Fashion (29 January to 29 February), moving to Sheffield and Belfast later in the year. See www. showstudio.com/wonderland. 